\title{
PROJETO DE UM SISTEMA SEMI-AUTOMATIZADO DE MEDIDAS DE POTENCIAL ELÉTRICO NATURAL OU INDUZIDO DO SOLO PARA APLICAÇÕES GEOELÉTRICAS
}

\author{
Francisco Yukio Hiodo' \\ Nilton Silva ${ }^{2}$ \\ Vagner R. Elis ${ }^{3}$ \\ Luis Galhardo Filho ${ }^{4}$ \\ Jorge E. da Silva ${ }^{5}$ \\ Recebido em 25 de mar., 2002 / Aceito em 28 de nov., 2003 \\ Received Mar. 25, 2002 / Accepted Nov. 28, 2003
}

\section{ABSTRACT}

The devices were developed to realize spontaneous and induce voltage measurement on the ground. In both case we used a multiwire cable with multiple voltage inputs along the length that becomes possible to conect it in six stainless electrodes fixed in the ground at same time. An automatic sequence digital system controlled by pushbutton touch allows to couple electrodes sequentially to a electronic DC voltmeter with autozeroing circuit based in PID servocontrol circuit. A 60 $\mathrm{Hz}$ notch filter and a roll-off low pass filter with time constant of $\mathrm{Is}$ are used to minimize line and spheric noises. Electronic control system becomes too possible to couple cable with receiver datalogger of SYSCAL R-2 in dipole- dipole sounding array.

Keywords: Spontaneous and Induce Voltage Measurement, PID Servo control.

\section{RESUMO}

Os equipamentos foram desenvolvidos para efetuarem medidas de potenciais espontâneo e induzido na superfície. Em ambos os casos foi usado um cabo multifio com entradas múltiplas de tensão ao longo do comprimento, que tornou possível conectá-lo a 6 eletrodos de aço inox cravados no solo. Um sistema digital de seqüenciamento automático controlado por mini interruptor de pressão permite acoplar os eletrodos de potencial seqüencialmente para um voltímetro eletrônico $D C$ com circuito de autozeramento baseado em circuito de servocontrole PID. Um filtro ativo tipo rejeição de $60 \mathrm{~Hz}$ e um tipo passa-baixa com constante de tempo de 1 segundo são usados para minimizarem os ruídos de linha e os esféricos. 0 sistema de controle eletrônico torna também possível acoplar 0 cabo multifio com 0 receptor datalogger do SYSCAL R-2 no arranjo para caminhamento dipolo- dipolo.

Palavras-chaves: Caminhamento dipolo-dipolo, Comutador de eletrodos de potencial, Servo controle PID, Potencial espontâneo.

IAG/USP. Departamento de Geofísica - Rua do Matão 1226 - Cidade Universitária - São Paulo - SP - 05508-090 - Tel.: (11) 30914777 -Fax: (11) 30915034 E-mail: francisc@iag.usp.br.

2 IAG/USP. Pós-graduação em Geofísica - Rua do Matão 1226 - Cidade Universitária - São Paulo - SP - 05508-090 - Tel.: (11) 30912847 -Fax: (11) 30915034 E-mail: nilton@iag.usp.br.

3 IAG/USP. Departamento de Geofísica - Rua do Matão 1226 - Cidade Universitária - São Paulo - SP - 05508-090 - Tel.: (11) 30914734 -Fax: (11) 30915034 E-mail: vagnelis@iag.usp.br.

4 IAG/USP. Departamento de Geofísica - Rua do Matão 1226 - Cidade Universitária - São Paulo - SP - 05508-090 - Tel.: (11) 30912827 -Fax: (11) 30915034 E-mail: galhardo@iag.usp.br.

5 IAG/USP. Pós-graduação em Geofísica - Rua do Matão 1226 - Cidade Universitária - São Paulo - SP - 05508-090 - Tel.: (11) 30914775 -Fax: (11) 30915034 E-mail: quartafeira@hotmail.com. 


\section{INTRODUÇÃOO}

Atualmente, as sondagens geoelétricas usando corrente chaveada são intensivamente empregadas na localização de descontinuidades laterais e no delineamento de camadas em subsuperficie. Elas competem com os métodos eletromagnéticos, que permitem levantamento mais rápido, mas não trazem informações do teor de argila no solo. Os caminhamentos clássicos nos arranjos pólo-dipólo, dipólo-dipólo, operam com tensões elevadas e necessitam de vários cabos de conexão, que podem induzir a erros de posicionamento de eletrodos, durante uma prospecção mineral. Com o intuito de minimizar o número de operações, isto é, reduzir o risco de erros, foram desenvolvidos e montados um cabo flexível com múltiplas entradas ao longo de seu comprimento e um circuito de comutação seqüencial digital comandado por interruptor de pressão para medida de potencial dos vários eletrodos, não-polarizáveis ou de aço inox. A saída desse circuito pode ser acoplada a um milivoltímetro de 3 1 12 dígitos dotado de circuito de realimentação negativa e filtros ativos para medida de potencial espontâneo ou então, a um receptor (dataloggen) de um eletrorresistivímetro (por exemplo Syscal R-2) de corrente chaveada, para medidas de potencial induzido no solo.

\section{METODOLOGIA - INSTRUMENTAÇÃO}

Nos trabalhos de caminhamento elétrico dipólo-dipólo, os eletrodos de potencial (ou de corrente) são conectados alternadamente ao longo de uma linha, necessitando, portanto, do apoio contínuo de um operador. Portanto, torna-se um trabalho tedioso, sujeito a eventuais erros.

Uma alternativa seria a confecção de um cabo com múltiplas entradas que permitiria conexão com os eletrodos numa única etapa. Portanto, com o recurso do cabo, o intercâmbio dos eletrodos deixaria de ser manual, para ser feito através de comutadores eletromecânicos (relés ou chaves analógicas). Para evitar possíveis erros de combinação de eletrodos, foi adotado um circuito de comutação seqüencial comandado por lógica digital. Na primeira etapa do projeto, foi desenvolvido um cabo com seis vias, para investigação em seis níveis de profundidade no arranjo dipólo-dipólo ou então efetuar medidas seqüenciais de potencial em seis pontos escolhidos.

0 cabo múltiplo de $10 \mathrm{~mm}$ de diâmetro, possui entradas a cada 10 metros, de cobre coberto com uma película de níquel que proporciona maior dureza e proteçãa contra oxidação. A cobertura de Ni confere uma boa dureza, que permite 0 uso de conectores jacaré para conexão com os eletrodos de aço inox cravados no solo.
No caso de investigação com tensão $D C$, foi desenvolvido um circuito de leitura de $3 \frac{1}{2} 2$ dígitos, com resolução de $100 \mathrm{nV}$, dotado de circuito de servocontrole PID (proporcional-integral-derivativo), que permite 0 autozeramento do potencial de contacto eletrodo-solo, por simples toque num interruptor de pressão. Como o circuito está dotado de filtro rejeição de $60 \mathrm{~Hz}$, e filtros passa-baixo ativos de frequêencia de corte mínimo de $0,15 \mathrm{~Hz}$, a constante de tempo destes filtros é da ordem de 1,5s. Para se ter o valor correto de tensão, o tempo de medida deve ser da ordem de cinco vezes 0 valor dessa constante. № modo manual, o zeramento torna-se extremamente moroso devido ao valor dessa constante de tempo. Com o recurso do circuito de servorealimentação, o tempo de cancelamento do potencial eletroquímico (contacto eletrodo-solo) é da ordem de $5 \mathrm{~s}$ para uma deriva de $1 \mathrm{mV}$, em 15 minutos. Para facilidade de projeto, usou- se somente circuitos analógicos, no circuito de amostragem e retenção (sample and hold). Para se ter esta estabilidade temporal foi necessário usar anel de guarda na entrada do integrador (memória analógica) para reduzir os efeitos de corrente de fuga.

\section{DESCRIÇÃO DOS CIRCUITOS}

Para 0 comando seqüencial dos eletrodos foi desenvolvido um circuito digital descrito a seguir.

0 circuito de chaveamento dos eletrodos fixados no solo (Figura 1) é formado de um multivibrador monestável usando duas portas NOR (CD4001) que evita possíveis repiques da chave mecânica PULSO. A saída deste pulsador é aplicada na entrada CLK do circuito Johnson ou contador em anel (CD 4017), responsável pelo modo seqüencial dos eletrodos de medida de potencial elétrico. As sá́das seqüenciais são aplicadas nos transistores NPN, que excitam os relés, responsáveis pela comutação, através do acionamento da chave SP/DP (modo potencial espontâneo ou dipólo-dipólo).

As medidas de potencial no modo $D C$ são feitas por um milivoltímetro desenvolvido no IAG, onde foram usados capacitores de policarbonato de baixa fuga, amplificadores operacionais BIFET quádruplos de alto desempenho, baixo ruído e baixo consumo. Para usar uma única fonte de $9 \mathrm{~V}$ foi montado um circuito que proporciona uma alimentação simétrica $\pm 4,5 \mathrm{~V}$, suficiente para polarizar os circuitos amplificadores e filtros ativos, que consomem $10 \mathrm{~mA} \mathrm{no} \mathrm{total.}$

Na Figura 2, um resistor R de 500W é inserido em série com as resistências do solo (entre os dois eletrodos de medida) e do amplificador diferencial de entrada. Nos extremos deste resistor estão conectados as saídas de dois circuitos seguidores de tensão, responsáveis pela tensão de cancelamento do potencial eletroquímico eletrodo-solo. Esta tensão 


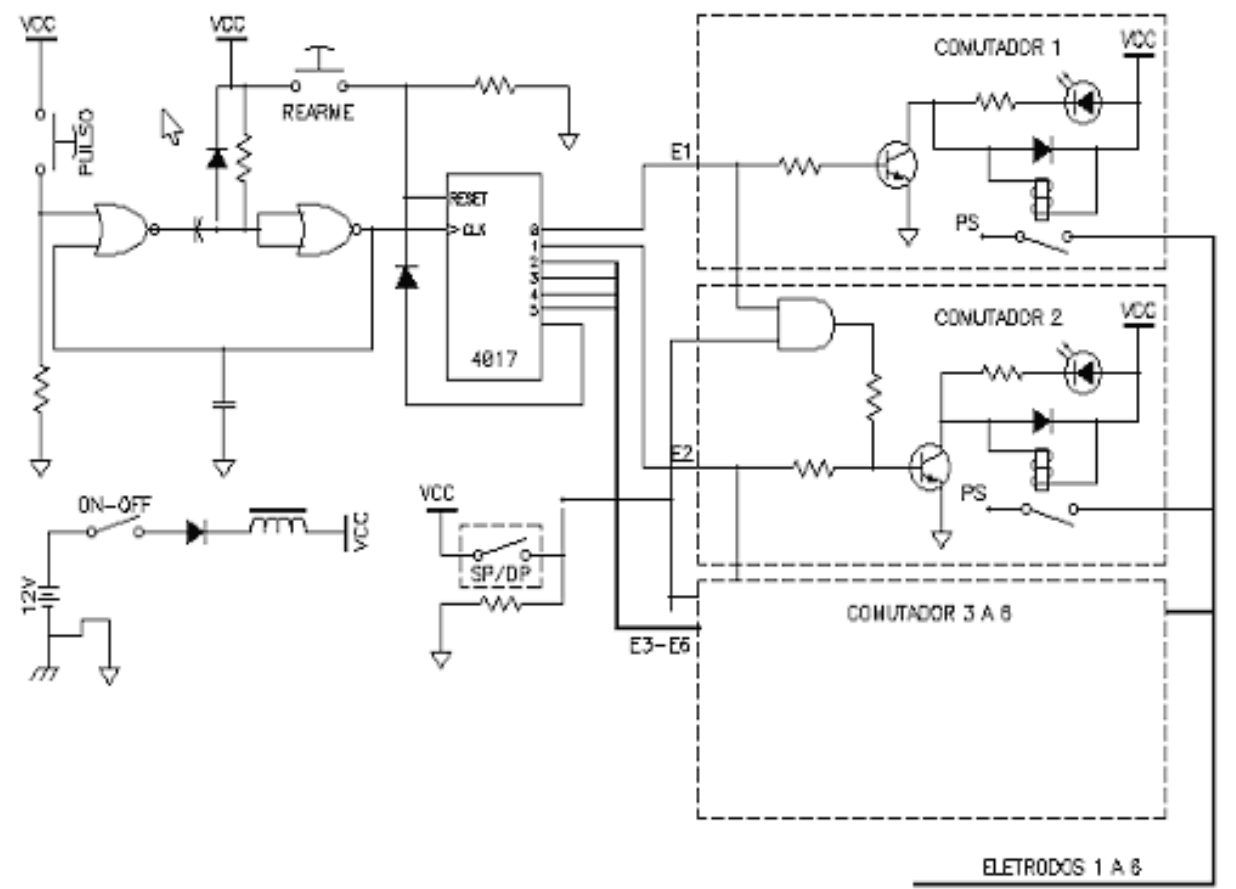

Figura 1- Diagrama esquemático do circuito de comando seqüencial dos eletrodos de potencial elétrico do solo. Figure I - Schematic diagram of sequential controller circuit of electrical potencial electrodes fixed in the soil.

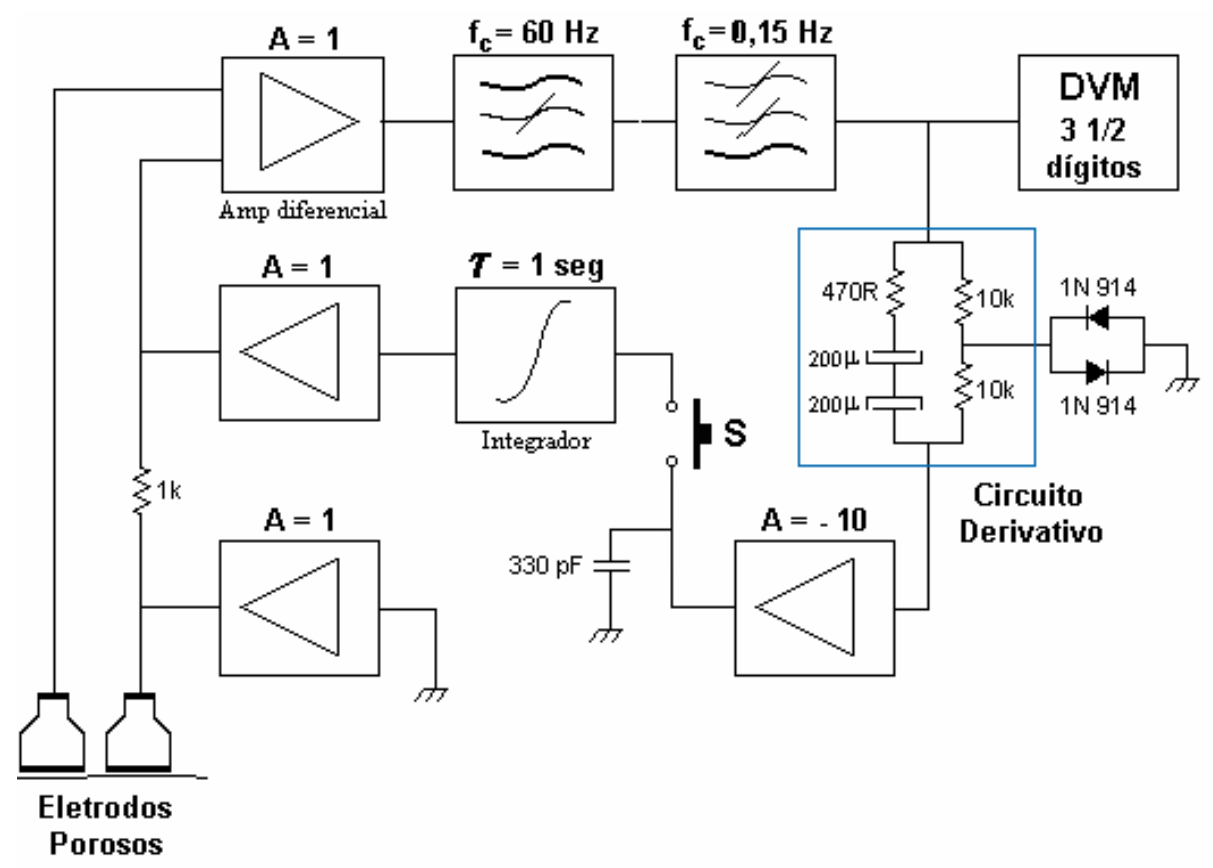

Figura 2 - Circuito de zeramento usando servocontrole PID e memória analógica, para medida de potencial DC do solo. Figure 2 - Autozeroing circuit based in PID servo control and analogic memory to DC potential measurement on the soil. 
de cancelamento poderia ser aplicada diretamente no resistor de realimentação do amplificador diferencial, que produziria o mesmo efeito. Contudo, esta configuração não foi adotada para não interferir na razão de rejeiçã̃o em modo comum CMRR desse amplificador, o que poderia afetar 0 ruído de entrada do circuito.

Na saída do amplificador diferencial de ganho unitário e impedância de entrada de 4 MW, estão conectados em sequiência (cascata): um filtro rejeição centrado em $60 \mathrm{~Hz}$, um filtro passa baixo de frequeência de corte de $1,5 \mathrm{~Hz}$ e um filtro passa baixo roll-off com frequêencia de corte de $0,15 \mathrm{~Hz}$, para redução do efeito dos esféricos (micropulsaçōes, correntes telúricas etc)

A seguir, existe um circuito de ação derivativa e proporcional para linearizar a função de transferência total do elo de feedback, e introduzir um amortecimento crítico no estágio de autozeramento. Este circuito de cancelamento é introduzido momentaneamente no elo de realimentação, através de interruptor $S$, que deve ser pressionado por cinco segundos, até a convergência para zero,. da tensão de saída do filtro roll-off. Uma vez zerado, a chave S é liberada, estando o circuito pronto para medidas de tensão dos eletrodos de potencial, através de um milivoltímetro DVM de 3 1 1/2 dígitos.

\section{OPERAÇÃO NO CAMPO}

Primeiramente são cravados os dois eletrodos de corrente e os eletrodos de medida de potencial, cujo número depende da profundidade de investigação. Este arranjo retilíneo de eletrodos eqüidistantes é orientado, de modo a cruzar transversalmente a descontinuidade geológica de interesse. A seguir, conecta-se os eletrodos de corrente (aço inox) à fonte e estende-se o cabo de múltiplas entradas ao longo da linha de eletrodos (aço inox) de medida do potencial elétrico. Então, essas entradas são conectadas aos eletrodos de medida através de garras jacaré. Como essas comutações são feitas seqüencialmente por um pequeno toque na chave $S$, a possibilidade de erro é minimizada. Após 0 término desse grupo de medidas, 0 cabo é facilmente arrastado por 10 metros, para uma nova sequiência. Isto reduz 0 tempo total de um levantamento geoelétrico e diminui a possibilidade de erros, nessa sequiência tediosa e cansativa de medidas no campo.
Para medidas de potencial espontâneo, usando eletrodos nãopolarizáveis de $\mathrm{CuSO}_{4^{\prime}}$ onde não é injetado corrente no solo, 0 procedimento é idêntico, bastando o acionamento da chave seletora.DP/ SP, do circuito comutador (Figural).

\section{COMENTÁRIOS}

0 sistema desenvolvido foi utilizado em trabalho de delimitação do polvente churume, num lixão já desativado em Ribeirão Preto-SP, com sucesso. A sua utilização reduziu apreciavelmente 0 tempo de trabalho de campo.

Nessa fase do projeto evitou-se o uso de microcontroladores da família do $82 C 51$ ou PIC, para facilitar a execução e solucionar um problema urgente. Futuramente estes microcircuitos com memórias RAM, EEPROM e Flash programados em linguagem ( ser̃a empregados para controle do circuito contador em anel CD4017, e de um conversor AD de 12 bits para conexão com um notebook, através de saída paralela da impressora.

\section{REFERÊNCIAS}

BASTIANON, D. Desenvolvimento de um sistema de medida de resistividade elétrica complexa para aplicações geofísicas. 1996. Dissertação (Mestrado)-Instituto de Astronomia, Geofísica e Ciências, Universidade do Estado de São Paulo, São Paulo, 1996. p. 80.

FIGINI, G. Eletrônnica industrial:servomecanismos. São Paulo: Hemus, 1992.

FROHR, F.; ORTTENBURGER, F. Técnicas de controle eletrônico: controle automéatico para acionamentos reguláveis de corrente contínua. Manual Siemens. São Paulo: Nobel, 1990. p. 320

HIODO, F. Y.; RIBEIRO, F. B.; ROQUE, A. Desenvolvimento de sistema de controle de gamaespectrômetro de $\mathrm{Nal}$ (TI). In: CONGRESSO INTERNACIONAL DA SOCIEDADE BRASILEIRA DE GEOFISICA, 3., 1993, Rio de Janeiro. Anais.. [Rio de Janeiro: s.n.], 1993. v. 2. p. 865-870. TELFORD, W. M.; GELDART, L. P.; SHERIFF, R. E. Applied Geophysics. New York: Cambridge University Press, 1986. 


\section{NOTAS SOBRE OS AUTORES}

Francisco Yukio Hiodo é graduado em Física pelo Instituto de Física da Universidade de São Paulo-USP em 1972. Mestrado em Geofísica pelo Instituto de Astronomia, Geofísica e Ciências Atmosféricas (IAG-USP) em 1981. Doutorado em Geofísica pelo IAG-USP em 1990. Auxiliar de Ensino no IAG-USP em 1973. Professor Assistente em 1981. Professor Doutor do IAG-USP desde 1990. Atualmente é especialista em Instrumentaçãa Geofísica nas áreas de: Paleomagnetísmo (magnetômetros rotativos e desmagnetizadores), Geofísica Nuclear (espectrômetros gama e emanômetros de radônio), Perfilagem de poços tubulares, Geotermometria e sensores de temperatura, Magnetômetros de precessão de prótons e fluxgate, Métodos geoelétricos e eletromagnéticos.

Nilton Silva trabalhou de 1985 à 1987 como técnico em Eletrônica na empresa Digimed Ind. Eletrônica. Trabalhou 10 anos como técnico em Eletrônica e Telecomunicações na empresa EMBRATEL, nas áreas de Telecomunicação de dados, Transmissão Digital e Satélite. Bacharel em Geofísica pelo Instituto de Astronomia, Geofísica e de Ciências Atmosféricas da Universidade de São Paulo (IAG-USP) em 2002. Atualmente está desenvolvendo sua pesquisa de Mestrado em Geofísica no IAG-USP, na área de Instrumentação em Geofísica Nuclear, intitulada: "Construção de um Espectrômetro Gama para Aplicações em Geofísica Ambiental e Dosimetria".

Vagner Roberto Elis é graduado em Geologia em 1990 pela Universidade Estadual Paulista. Mestre em Geociências pela Universidade Estadual Paulista em 1993 desenvolvendo a dissertação "A aplicação da geofísica para análise do meio físico: Importância para elaboração de mapeamento geotécnico". Doutor em Geociências pela Universidade Estadual Paulista em 1999 defendendo a tese "Avaliação da aplicabilidade de métodos elétricos de prospecção geofísica no estudo de áreas utilizadas para disposição de resíduos". Docente do Departamento de Geofísica do Instituto de Astronomia, Geofísica e Ciências Atmosféricas da Universidade de São Paulo, com atuação nas áreas de Geofísica Aplicada a estudos ambientais e hidrogeológicos.

Luis Galhardo Filho é formado em 1983 como Técnico Eletrônico pela Escola Técnica Getúlio Vargas. De 1983 a 1991 trabalhou como técnico em eletrônica no Instituto de Astronomia, Geofísica e Ciências Atmosféricas da Universidade de São Paulo (IAG-USP), nas áreas de desenvolvimento e apoio técnico em Eletrônica. Em 1990 formou-se em Engenharia Elétrica, modalidade Eletrônica, pela Faculdade de Engenharia São Paulo (FESP). Desde 1991 trabalha no IAG-USP como Engenheiro do Departamento de Geofísica.

Jorge Eduardo da Silva é bacharel em Geofísica pelo Instituto de Astronomia, Geofísica e de Ciências Atmosféricas da Universidade de São Paulo (IAG - USP) em 2003. Atualmente trabalha como Geofísico na área de aquisição, processamento e interpretação de dados geofísicos junto à empresa AeroGeoPhysica Latinoamerica (AGP - LA). 